\title{
COVID-19 infections and pulmonary rehabilitation
}

\author{
Ijpek CANDEMIR ${ }^{\mathbf{1}}$ (ID) \\ PInar ERGÜN²(ID)
}

Cite this article as: Candemir i, Ergün P. COVID-19 infections and pulmonary rehabilitation. Tuberk Toraks 2020;68(2):192-194.

\section{Yazışma Adresi (Address for Correspondence)}

Dr. İpek CANDEMIR

Ankara Atatürk Göğüs Hastalıkları ve Göğüs Cerrahisi Eğitim ve Araştırma Hastanesi,

Pulmoner Rehabilitasyon ve Evde Bakım Merkezi, Ankara, Türkiye

e-mail: ipekcayli@yahoo.com

CCopyright 2020 by Tuberculosis and Thorax.

Available on-line at www.tuberktoraks.org.com
${ }^{1}$ Pulmonary Rehabilitation and Home Care Center, Ankara Atatürk Chest Diseases and Chest Surgery Training and Research Hospital, Ankara, Turkey

${ }^{1}$ Ankara Atatürk Göğüs Hastalıkları ve Göğüs Cerrahisi Eğitim ve Araştırma Hastanesi, Pulmoner Rehabilitasyon ve Evde Bakım Merkezi, Ankara, Türkiye

${ }^{2}$ Clinic of Chest Diseases, Ankara Atatürk Chest Diseases and Chest Surgery Training and Research Hospital, Ankara, Turkey

2 Ankara Atatürk Gögüs Hastalıkları ve Göğüs Cerrahisi Eğitim ve Araştırma Hastanesi, Göğüs Hastalıkları Kliniği, Ankara, Türkiye
Severe acute respiratory syndrome coronavirus 2 (SARS-CoV-2) is a new coronavirus that emerged in 2019 and causes coronavirus disease 2019 (COVID-19). SARS-CoV-2 is highly contagious and it was declared as a pandemic disease by World Health Organization (WHO) (1). Since first patient was diagnosed in Turkey on 11th of March, the declared total number of cases has been 78.546 where 1845 of them are in the intensive care unit and 1014 of them have been intubated according to data of Turkish Ministry of Health on $17^{\text {th }}$ of April (2). It has ben reported that $80 \%$ of COVID-19 positive patients have had mild to moderate disease regardless of having pneumonia, $13.8 \%$ have had severe disease and $6.1 \%$ of them have had severe disease which has resulted in respiratory failure, septic shock, and/or multiple organ dysfunction/failure $(3,4)$. As a pandemic disease, COVID-19 infection has been expected to be a cause for critically ill with acute respiratory distress syndrome (ARDS) and need for management in intensive care units (ICUs) in the large numbers of patients (5). High levels of physical, cognitive and psychosocial impairments which are associated with age, comorbidities, disease severity can be anticipated. Due to the need for holistic and multidisciplinary approach in management of COVID-19 infection, pulmonary rehabilitation (PR) which meets individual needs are seemed to be an effective intervention in these 
patients. It has been unclear to whom, where, how and when to perform PR consisting exercise training, bronchial hygiene techniques, nutritional assessment support, psychosocial assessment support, patient and family education, oxygen therapy, noninvasive and invasive mechanical ventilation.Current information and recommendations regarding PR programs in COVID-19 disease are predominantly as an expert opinion. It is recommended that patients should be assessed individually and individual approachs should be conducted by using personal protective equipment in acute and post-acute period (4-6). The recommendations on the content of PR programs are different according to disease severity.

\section{PR in Acute COVID-19 Infections}

Assessments: Before PR, the assessments can be performed by easily applicable tests, such as the Short Physical Performance Battery, 30 Seconds Sit-to-Stand test, handgrip dynamometer test and/or a manual muscle strength test. Additionally cardiac side effects and presence of tromboembolism should be investigated (6-8).

PR programs: In a sympthomatic patients or having symptoms without pneumonia, advices on quiting smoking, healthy sleeping and nutritional habits and avoiding physical inactivity are recommended during quarantine period (7). Patients with mild pneumonia and with/without comorbidities, have indications of PR in order to improve symptoms such as dyspnea, anxiety and depression, physical activities and quality of life. In these patients, mobilization and exercise training including bed mobility, sitting out of bed, sitting balance, sit to stand, walking, tilt table, standing hoists, upper/lower limb ergometry and resistance training might be applied (6-8). It has been reported that airway clearance techniques were not required due to the non productive cough in most cases (9). Airway clearance techniques should be applied in presence of mucus hypersecretion, exudative consolidations and underlying bronchiectasis with personel protective equipmentin isolated rooms or negative pressure rooms, if possible $(6,7)$. In intensive care unit (ICU) period therapeutic positioning (early sitting, prone positioning), pasive or active mobilization, range of motion exercise, neuromusculer electrical stimulation (NMES) could be performed as a part of PR $(1,4-9)$. In patient with critical disease, diaphragmatic breathing, pursed lips breathing, bronchial hygiene/ lung re-expansion techniques, incentive spirometer; manual mobilization/stretching of the rib cage, respiratory muscle training, exercise training are not recommended in order not to increase the work of breathing (9). In ICU patients, another important components of PR are psychological and nutritional evaluation and supports. Cognitive functions should be followed. Every critically ill patient staying for more than $48 \mathrm{~h}$ in the ICU should be considered at risk for malnutrition. Nutritional support should meet increased energy expenture $(10,11)$.

\section{PR in Post-Acute COVID-19 Infections}

Most of patients who receive care in an intensive care unit may have post-intensive care syndrome (PICS) defined as new or worsening impairments in physical, cognitive, or mental health status a rising after critical illness and persisting beyond acute care hospitalization. The greatest change in physical function after a diagnosis of acute respiratory failure has been shown to occur within the first two months after discharge (12). Muscle loss, frailty, and sarcopenia are associated with decreased quality of life at 6 and 12 months post$\mathrm{ICU}$, as well as an increase in organ failure and mortality (13). Although, we have lack of data in long term effects of post-COVID-19 infections, PR would be requireddue to aforementioned reasons.

Assessments: Assessment should at least include measures that revealing of persistent physiological limitations (e.g., lung function, exercise and functional capacity, muscle function, balance) and patient-reported outcomes (e.g., symptoms and health-related quality of life). The effects of COVID-19 on respiratory, cardiovascular, musculoskeletal and nervous systems and accompanying comorbidities should be considered. Medical research council (MRC) muscle strength scale, manual muscle strength test, isokinetic muscle test, hand grip and range of motion (ROM) should be evaluated. Exercise capacity could be assessed by six-minute walk test (6MWT) (if available) or short physical performance battery and a 30-second sit-andstand test $(6,8)$.

PR programs: Patients with COVID-19 positive who are under home treatment or follow-up period andknown to need ofPR, only low-intensity physical activity/exercises including functional strengthening (dyspnoea and/or fatigue on modified 0-10 points Borg scale $\leq 3$ ) are recommendedduring the first 6-8 weeks at home (6). Tele-PR which has been recently per- 
formed in our country, might be consider in these patients. In prolonged hospitalization and prolonged weaning period, PR indication should be evaluated by the multidispliner PR of which the medical director is chest physician. Comprehensive PR programs containing exercise training, assessment of body composition nutritional supportive therapy, psychosocial assessment supportive therapy, balance tests, patients and family education should be performed with isolation rules and using personel protective equipments.

Many countries have a complete lock down, which most probably prevents participation in a regular outpatient PR program, supervised home based PR, need for rehabilitative interventions in COVID-19 survivors (6). Tele-PR especially hospital based synchronous "face-to-face" interactive video conferencing via internet model is seemed to be an important alternative model during pandemic and post- pandemic period according to predicted increased demands. PRcenters/ units in which chest physicain is medical director should put into practice this model and patients should refer to this centers/units.

\section{REFERENCES}

1. World Health Organization. Clinical management of severeacute respiratory infection (SARI) when COVID-19 disease issuspected. Interim Guidance, 2020. WHO Reference number WHO/2019-nCoV/clinical/2020.4

2. T.C. Sağlık Bakanlığı Türkiye'deki güncel durum. Korona tablosu. https://covid19.saglik.gov.tr/

3. COVID-19 (SARS-CoV2) infeksiyonu Rehberi (Bilim Kurulu Çalışması). T.C. Sağlık Bakanlığı Halk Sağ/ı̆̆ı Genel Müdürlüğ̈̈̈. (https://covid19bilgi.saglik.gov.tr/depo/rehberler/COVID-19_Rehberi.pdf) 14 Nisan 2020.

4. Jin YH, Cai L, Cheng ZS, Cheng H, Deng T, Fan YP, et al., for theHospital of Wuhan University Novel Coronavirus Managementand Research Team, Evidence-Based Medicine Chapter ofChina International Exchange and Promotive Association forMedical and Health Care (CPAM). A rapid advice guideline forthe diagnosis and treatment of 2019 Novel Coronavirus (2019-nCoV) infected pneumonia (Standard Version). Mil Med Res 2020;7(1):4.
5. Simpson $R$, Robinson L. Rehabilitation following critical illness in people with COVID-19 infection. American Journal of Physical Medicine \& Rehabilitation: 2020 April 10, Publish Ahead of Print - Issue -doi: 10.1097/ PHM.0000000000001443.

6. Spruit MA, Holland AE, Singh SJ, Troosters T. Report of an Ad Hoc International Task Force to develop an expertbased opinionon early and short-term rehabilitative interventions (aftertheacute hospital setting) in COVID-19 survivors. https://ers.app.box.com/s/npzkvigt/4w3pbOvbsth4y0fxe7ae9z9.

7. Zhonghua Jie He He Hu Xi Za Zhi. Recommendations for respiratory rehabilitation of COVID-19 in adult. Chinese Association of Rehabilitation Medicine; Respiratory rehabilitation committee of Chinese Association of Rehabilitation Medicine; Cardiopulmonary rehabilitation Group of Chinese Society of Physicai Medicine and Rehabilitation. 2020 Mar 3;43(0):E029. doi: 10.3760/ cma.j.cn112147-20200228-00206. [Epub ahead of print]

8. Thomas P, Baldwin C, Bissett B, et al. Physiotherapy management for COVID-19 in the acute hospital setting: clinicalpractice recommendations. Journal of Physiotherapy 2020. doi: https://doi.org/10.1016/j.jphys.2020.03.011.

9. Lazzaeri $M$, Lanza A, Bellini R, Bellofiore A, Cecchetto $S$, ColomboA, et al. Respiratory physiotherapy in patients with COVID-19infection in acute setting: a position paper of Italian Associationof Respiratory Physiotherapists. Monaldi Arch Chest Dis 2020;90:1285. doi: 10.4081/ monaldi.2020.1285.

10. Singer $P$, Reitham Blaser $A$, Berger MM, et al. ESPEN Guidelines: nutrition in the ICU. Clin Nutr 2018;38:48-79.

11. Singer P. Preserving the quality of life: nutrition in the ICU. Critical Care 2019;231:139 https://doi.org/10.1186/ s13054-019-2415-8.

12. Smith $M M$, Lee $A C$, Zeleznik $H$, Scott JP, Fatima $A$, Needham DM, et al. Home and community-based physical therapist management of adults with post-intensive care syndrome. Physical Therapy 13 April 2020. https:// doi.org/10.1093/ptj/pzaa059

13. Muscedere J, Waters B, Varambally A, Bagshaw SM, Boyd $G$, Maslove $D$, et al. The impact of frailty on intensive care unit outcomes: a systematic review and meta-analysis. Intensive Care Med 2017;43:1105-23. 